\title{
LA GASTRONOMÍA EN LIMA \\ DESDE 1950: de tamales y chifas
}

\author{
Humberto Rodríguez Pastor
}

\section{Resumen}

En este artículo se explica por qué solo en las últimas cinco décadas los peruanos "descubrimos" que tenemos una buena y variada cocina, fenómeno positivo de nuestra autoestima que surge a partir de las grandes migraciones internas. De las diferentes corrientes culinarias en el país se presenta un platillo: pan peruano, el tamal. Hay referencias a su historia y se muestra cómo Lima, gran mercado gastronómico nacional, atrae y ofrece distintos tamales provincianos. Otra corriente de gran consumo, aunque no exclusivamente limeño, es el fenómeno de la comida china cantonesa y de los chifas, caso único en toda América. Este tipo de comida con frecuencia y desde hace algún tiempo se elabora en los hogares y con naturalidad los insumos se ofrecen en los mercados.

Palabras claves: culinaria, tamal, comida china, chifa.

\section{Cómo Lima dejó de ser la Ciudad de los Reyes}

Durante el gobierno del general Manuel A. Odría, entre 1948 y 1956, el denominado Ochenio, hubo en el país un crecimiento de los ingresos del erario público, debido a que aumentaron considerablemente las exportaciones de nuestras materias primas. Era la época de la guerra en Corea en la que Estados Unidos estuvo metido, ¡cuando no!, y nos compraba en cantidad muchos productos. 
Con el aumento de ingresos el Estado Peruano realizó obras en Lima que, para entonces, eran impresionantes, por ejemplo las unidades vecinales y las grandes unidades escolares. Sucedía además la silenciosa desestructuración económica en el interior, causa que expulsaba a la gente a migrar, por ello muchas personas de provincias muy fácilmente encontraba trabajo en Lima, es así como por esos años aumenta el transvase migratorio hacia esta ciudad. La capital peruana, que en el año 1940 tenía 828 mil habitantes, pasó a tener una población en 1963 de 2 millones; y en 1972 los que residían en esta ciudad eran 3.5 millones. Miles y miles de provincianos fueron llegando a Lima, corriente migratoria que aún no cesa. Lima actualmente tiene 9 millones de habitantes, es decir 10 veces más que el año 1940.

Me parece conveniente tomar una acertada cita del sociólogo Pedro Pablo Ccopa, quien al tener en cuenta lo que ha ocurrido con la capital peruana dice: "Lima es una identidad múltiple, una creación de lo múltiple, de los migrantes. Es una ciudad muy particular, que no pertenece a un patrón o a un amo. Es casi como que los migrantes hubieran tomado Lima como para botar de ella a los conquistadores".

Teniendo en cuenta el tema de este artículo lo que nos interesa de esta masiva migración interna a Lima y de la cita de Ccopa es que junto con la gente de provincias llegaron también su paladar, su culinaria y su gastronomía que de alguna manera desplazaron la tradicional comida limeña y revolucionaron el orden culinario, gastronómico, alimenticio. Ya aquí en Lima, los arequipeños ofrecieron al resto de migrantes su rocoto relleno y su cuy chactado; los huancaínos como sea calentaron las piedras, hicieron sus humitas y su japche y ofrecieron a todos su gratísima pachamanca; la patasca comenzó a comerse en muchos lugares, incluso en huariques y en mercados; los juanes aparecieron en ciertos restaurantes de comida amazónica, y se hizo famoso el Rinconcito Cajamarquino en el Rímac. La comida criolla fue consumida en grandes cantidades en el Rosita Ríos que tenía su local también en el Rímac, y en el Tumbes Mar se podía degustar el arroz con conchas negras así como inmensos cebichazos, incluso el cebiche de conchas negras se podía encontrar muy fácilmente por las calles y avenidas de la capital que crecía cada día más, a la par que se provincializaba también cada día más.

Y sin darnos cuenta aparecieron restaurantes con comida de muchas partes del Perú o clubes departamentales donde se podía saborear las viandas de cada departamento. Al mismo tiempo aparecieron numerosos lugares donde se comía los pollos a la brasa; al final de ese banquete consumido con las manos se le presentaba al comensal un lavatorio chico con agua tibia y limón para que no llevara por las calles el olor a pollo a la brasa. Y el chifa se descontroló, salió del barrio chino y se fue a Miraflores, a Jesús María, al Rímac, a Surquillo, y el desborde de los chifas fue tal que en la actualidad, como todos podemos comprobar, no hay barrio que no tenga su chifa que, aunque sea, vende su chaufa y su aeropuerto a muy bajo costo. Algo parecido ha ocurrido con el cebiche y los mariscos: hay por todos lados y a precios al alcance de todos los bolsillos, hasta se encuentra cebiche de pota a un sol, con canchita y choclo pero sin camote cuando está caro.

El fenómeno que ha ocurrido es que los platillos de provincias al llegar a Lima han sido conocidos por los neolimeños, por los alimeñados, por los limeños de 
primera generación y por los limeños de más de una generación. Así, las viandas o manjares de provincias han dejado de ser regionales y se han peruanizado.

Y Lima se ha convertido en un lugar donde hay miles de platos exquisitos que antes, hace 50 años, no se conocían y que hasta se les veía con menosprecio.

Esto es una cosa grandiosa, la capital del Perú es una gran mesa donde están servidos los platos provincianos que uno desee. Para decirlo en palabras de Carlos Páucar, un cronista de La República: "Lima ya no es la horrible. Lima es la sabrosa, la gourmet, la exquisita".

Si cualquiera de nosotros se echa a caminar por las calles limeñas puede ver a vendedores callejeros que ofrecen puspu, mote, habas, choclos sancochados y camotes al horno chorreando su miel llamados pavita que se les encuentra por el centro de la ciudad, al igual que el sanguito, ese dulce secular de los afroperuanos que lleva pasitas y mistura. Por las calles también camina algún vendedor del italiano pastel de acelgas, y muy fácilmente se encuentra palta fuerte, jugo de naranja para el desayuno, huevos sancochados servidos en panca con papa y uchucuta; en ciertas vías se huele los aromosos chicharrones con camote frito tanto de chicharroneras que los expenden en las calles como en locales fichos sanisidrinos, y muy fácilmente hallamos tamales de muchas partes (Chincha, Supe, Mala, Huaral, Surco) que pueden adquirirse en las puertas de las panaderías o de pregoneros que los llevan en baldes que son generalmente cajamarquinos. Y si esos tamales son de Chincha la tamalera vendedora también ofrece carne de membrillo, maní sancochado, las sabrosas frutas de su campiña: guanábana, chirimoya, pacae, níspero, guayaba (fruta que se va extinguiendo), ciruelas y en verano uva borgoña y después uva italia. Y todo esto junto en un mismo lugar -Parque de la Exposición en el mes de septiembre- es ahora posible encontrar cuando la Asociación Peruana de Gastronomía (Apega) organiza las ferias mistura

Y si hablamos de locales, hay restaurantes y huariques de casi todas partes del Perú. Hay avenidas de puros restaurantes que el comensal puede escoger a su gusto, teniendo en cuenta cuánto lleva en su bolsillo.

Esta es la Lima gourmet, la capital gastronómica de América Latina.

En lo que sigue daremos información con mayores detalles sobre lo que ha sucedido en relación con los tamales y con la comida china y los chifas. El primero un platillo popular con muchos siglos entre nosotros, peruanizado con intensa fuerza tradicional imposible que pueda desaparecer pero sí variar en su sabor como viene ocurriendo; lo otro, la comida china, no tiene ni un siglo que entre los peruanos lo apreciamos y algunas de sus viandas se han peruanizado y han asumido una dinámica propia que es un fenómeno cultural-culinario-gastronómico por observar con ojos de antropólogo.

\section{Lejana muestra de interés gastronómico}

Aunque no parezca, interés por la buena comida se ha evidenciado en nuestro país, y preferentemente en Lima Metropolitana, en estas últimas 3 a 4 décadas, en anteriores años predominaba las preferencias gustativas-culinarias regionales y locales, con 
reglas estrictas con obligación de cumplirlas, y cualquier alteración a las normas de cocina no eran bien vistas. Como de años anteriores no hay la inmensa información como ahora sobre el interés del buen comer, nos llamó la atención un largo poema de 1844 titulado "El Gastrónomo" cuyo autor no es mencionado; la composición consta de seis sílabas en cada verso y es de rimado caprichoso que aparece cuando le viene en gana al poeta. El argumento tiene un protagonista, Benito, que espera en su casa a unos señores que llegarían acompañados, y este dueño de casa le va indicando a Marica o Mariquita, seguramente servidumbre, que prepare platillos y bebidas, y mientras los va sugiriendo, se va entusiasmando, y los va consumiendo y él será el único comensal que arrasará con todo; no se sabe —y no importa— si llegarían luego los invitados; importa la cantidad de viandas, frutas y vinos mencionados que Benito consumió. Actualmente, antes que denominar a este poema "El Gastrónomo", se le hubiera titulado "El gourmet", es decir, el que gusta del comer bien. Y como muestra de la escasa atención al tema, la composición se publicó solo cinco años después en un periódico limeño denominado El Progreso ${ }^{\top}$. Va la versión completa:

\section{El Gastrónomo}

$\begin{array}{ll}\text { Marica, ya llegan } & \text { se grave de suerte, } \\ \text { los tres caballeros } & \text { que solo se olvide } \\ \text { que anoche te dije } & \text { después de la muerte. } \\ \text { con sus escuderos. } & \text { Pero sí te advierto } \\ \text { Sácales jamones, } & \text { que aunque yo te pida, } \\ \text { y rico tocino, } & \text { de ninguna clase } \\ \text { buenos salchichones } & \text { me saques comida, } \\ \text { y un sabroso vino; } & \text { sino los potajes } \\ \text { grandes empanadas } & \text { que anoche escogí } \\ \text { y pavos rellenos, } & \text { para que pusieras } \\ \text { de modo que exclamen: } & \text { cuando estén aquí. } \\ \text { "iqué buenos!" "iqué buenos!" } & \text { Sí, ya me parece } \\ \text { Y en fin que se animen } & \text { que los estoy viendo } \\ \text { a chupar los huesos, } & \text { entrando a la cuadra } \\ \text { mojados y envueltos } & \text { y luego comiendo; } \\ \text { en sus aderezos. } & \text { y ya de acabarse } \\ \text { Y que ese gustillo } & \text { en coro cantar; }\end{array}$

1 El Progreso, N. ${ }^{\circ}$ 11, Lima, sábado, 13 de octubre de 1849, pp.7 y 8. 
que viva el buen vino del gran San Lucar.

Tal es lo contento, que yo voy a estar, que estando en la mesa nada he de tomar.

Sácame una tira del mejor pastel, porque estoy seguro que no he de comer. ¡Ah! ¡qué rica está! otra tira dame, tú los azafates, cuidadosa lame. Sácame un jamónYa se acabó — Otro- Por Dios, mi señor, que come cual potro.

—iQué buen gusto tiene! Ahora un gran cabrito.

De chancho te pido, Gordo, lomo, frito.

También un gran pavo, vino moqueguano.

¡Qué bueno! ¿Qué dulce! ¡Qué rico que está! Faltan salchichones, grandes camarones, gallinas asadas, ¡Ah! ya están aquí! ¡Santa Arauzaní! Si digo que vales, entero el Perú. Mas oye, te advierto, cierres las ventanas, que ese friecito, me quita las ganas. ¡Cerraste? - ya como con gusto el jamón, salchichones, lenguas, cual otro Milón. ¡Qué gusto tan suave! el de las empanadas, pero las gallinas, con qué tino asadas¡Ah! ¡Qué fuerte el vino! qué gusto tan rico tiene este tocino. Sácame más, hija, no tengas cuidado, que lo que me diste ya está rematado. -Pero, señor mío, usted me encargó, que solo sacase lo que señaló. —Bah! ¡qué tonterías! Saca que comer. ¡señor! —No porfíes despacha, mujer. —Vaya, tenga usted lo que aquí quedó, delicioso vino, del que Baco dio. -Gracias, Mariquita, brindo por mi humor. Si nunca he tomado tan grato licor¡Qué dulces granadas! ¡qué buenos limones! ¡qué blandos, jugosos los melocotones!. ¡Que viva! ¡que viva! la diosa Pomona que tan buena fruta. madura y sazona. -Marica, ¿no hay más? ya esto se acabó.

-No solo comida, $\mathrm{Ni}$ aun blanca, señor. — ¿Y qué caza es esa Que estoy viendo allí, saturada en salsa de picante ají? — ¡Señor! son los pollos que ha mandado asar, el padre Villegas, de Santo Tomás- 
- Que vengan los pollos, de su Reverencia, que él como buen monje, hará penitencia-

- No, señor, no puedo-

- Alcanza, mujer,

si por más que grites

los he de comer.

¡Qué ricos pollitos!

Si esto es un encanto;

sin duda es el monje

milagroso santo.

- ¿Qué llevan vendiendo, qué van pregonando?

Llámalo, que llegue;
Llámalo, que llegue;

y al punto comprarlo-

- Señor, don Benito,

su franqueza alabo,

si no hay ni un cuartillo, ni un solo centavo.

-Pues véndeme, pronto,

por una libranza, que solo deseo, llenarme la panza-

- Mas como ¿el convite?

lucido quedó.

porque usted, por prueba

todo lo acabó.

Lima, 1844

\section{Tamaleras limeñas, las provincianas y los supermercados}

El tamal es un producto comestible preparado artesanalmente; en el Perú tiene como sus principales componentes una masa de maíz molido, manteca y carne de cerdo o de pollo y es envuelto en algún tipo de hoja de tamaño considerable (panca, plátano, bijao, achira). Es de amplio consumo, sobre todo en sectores medios y populares y es de carácter panperuano. Lo elaboran las mujeres en casas, pueblos y ciudades. Cada una de ellas está segura de hacer el tamal más exquisito del mercado nacional; casi no perciben que la manera como lo elaboran y la sazón que ofrecen solo corresponde a los gustos de su pueblo o su región.

Lima ha tenido y tiene su propio tamal, que asumió características propias según los hicieran mujeres del distrito de Surco o mujeres afroperuanas, bajopontinas o chorrillanas. La creencia que es un platillo de la culinaria afro se debe a que en la capital las afronegras fueron notables vendedoras ${ }^{2}$ de esta y muchas otras viandas, que pregonaban con cantos y después a gritos.

El tamal siempre ha sido consumido en impresionantes cantidades durante las fiestas navideñas; esta misma preferencia de tiempos actuales se puede recordar o constatar cualquiera de los 25 de diciembre en los años anteriores y seguramente también en los próximos. Ricardo Palma en la tradición titulada "El mes de diciembre en la antigua Lima" es lacónico en su información: "A la misa de Gallo seguía en las casas opípara cena, en la que el tamal era el plato obligado".

2 En lo sucesivo escribiremos como si los personajes del tamal fuesen femeninos en tanto es lo más frecuente. 
Rosario Olivas, refiriéndose a Lima de mediados del siglo XIX, nos dice que "todos los domingos del año, los feriados y las noches buenas salía la tamalera llevando sus productos en canastones enceronados y bien acondicionados sobre un jumento”. En sus recorridos pregonaba así:

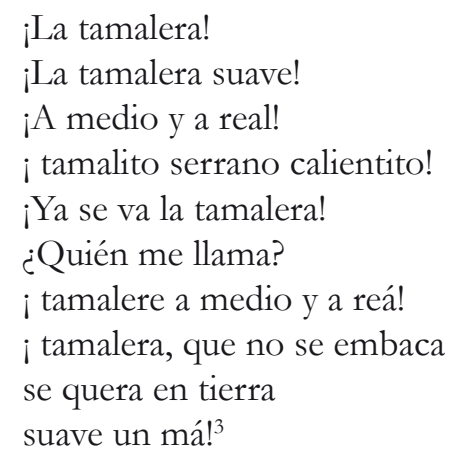

Sobre el mundo festivo de cierto grupo de hombres y mujeres negros de fines del siglo XIX, Pedro Benvenuto Murrieta informa que:

En efecto un poco de aguardiente y de cerveza... hacen dulce la vida de esta gente: tamaleras, lavanderas, amas de leche y de peones de hacienda, aguadores y cocheros de punto y particulares que forman las jaranas malambinas. Uno que otro faite suele, en veces, acabarla a capazos, pero es la excepción y no la regla. Cada oficio de los señalados tiene su cantor que en lenguaje vulgar hace su elogio. Canta uno:

Ya se va la tamalera.

Sobre su borrico va,

pregonando los tamales

A cuartillo y medio real.

Esta si que es de noche buena

Noche de Navidad,

iFrancisquito con Francisca

de su plata a disfrutar!

¡Ay mi amita!. Salga y compre

los tamales singulá

que le gustan al señorito

$Y$ a todos en generá.

Ya se va la tamalera

Sobre su borrico va,

\footnotetext{
3 PALMA, Ricardo. Tradiciones Peruanas Completas. pág.1198.
} 
Va vendiendo los tamales

Que hay de a medio y hay de a real.

Pasado medio siglo, el periodista Federico More en un artículo del año 1950 recordaba la solución que en el año 1910 había encontrado un grupo de literatos en horas de la noche cuando comenzaba apretar el estómago, ese grupo era tan pobre que:

... no podía darse el lujo de cenar. Y es así que descubrieron la cena barata. A las once menos cinco de la noche (ellos, los literatos) ocupaban dos bancas de la plaza de Armas, al frente del Portal de los Botoneros. A las once en punto salía, desembocando por la calle de Palacio el pregón de la tamalera suave, tamalera negra y bajopontina. No sabemos si la tamalera llegaba a las once o eran las once porque llegaba la tamalera. Veinte centavos cada tamal. Cada literato comía dos tamales. Cuarenta cobres y cena hecha. Alguno tenía que contentarse con un solo tamal por abominables razones crematísticas. Hoy los polvos y los líquidos insecticidas han dado muerte a los bichos familiares y caseros. ${ }^{4}$

Es así que en su particular historia el tamal en algún momento salió del consumo familiar y comenzó a venderse por las calles. Al comienzo los que vendían caminaban (callejeaban) en busca de clientes, iban anunciando sus productos, pregonaban por doquier las cualidades y los precios de sus tamales.

Todo esto de a pocos fue cambiando. Actualmente en Lima la mayoría de las tamaleras ha decidido no caminar; ellas han preferido ubicarse en las puertas de alguna panadería donde ofrecen sus tamales desde muy de madrugada, así en el día aparezca sol, haya neblina o llueva. Los consumidores limeños se han inclinado por un cambio de la carne fundamental: han rechazado la de cerdo y han escogido la de pollo. Estas vendedoras de tamales con pollo no pregonan más, prefieren entrar en la competencia de ganar clientes e incluso pretenden ganarlos hasta convertirlos en caseros cautivos.

Se es casero cuando se han realizado muchas compras a una misma vendedora estableciéndose entre la vendedora y la compradora una interrelación humana que no solo es económica. Entre ellas hay mutua confianza, hay algún grado de amistad, hay implícito cierto compromiso de comportamiento conocido de antemano, que no se reduce a la simple actitud mecánica de la compra-venta, y si hay incumplimiento de alguna de las partes se considera una pequeña traición inaceptable que puede romper o deteriorar así, por quítame esta paja, la relación de casería.

Las tamaleras para lograr una clientela cautiva utilizan una variedad de astucias, entre ellas: ofrecerles zarza de cebollas en buena cantidad o un bocadito de tamal que en la boca dure algo; concederles créditos por tiempos no muy lejanos; entregar su

\footnotetext{
$4 \quad$ Seguramente en ese grupo estuvieron los que participaron en la aventura literaria de la revista Colónida
} 
producto a parientes o servidumbre de sus caseros; en caso de mucha demanda guardarles algunos tamales; y si la compra es considerable conceder una notoria yapa; hay confianza que habrá pago si los pedidos, cualquiera sea la dimensión, son a través del celular, etc.

Por el contrario, los denominados supermercados e hipermercados que van en aumento en Lima Metropolitana y por igual fuera de la Capital, en realidad son all selfservice que matan al pequeño comercio próximo que puede haber a tres cuadras a la redonda, tienen multitud de clientes habitúes pero no tienen un solo casero. Para que haya una relación de casería se requieren dos personas, y en estos selfservices no hay posibilidad de alternar con un vendedor; no hay con quien intimar, no hay con quien compartir conversación, confianza para pedir al fiado, no hay a quién hacerle confidencias ni hay quien trasmita los chismecillos del barrio. Imposible lograr algo de esto en un súper o hípermercado. Es así porque a estos mercados modernos no les importa la casería, les interesa la cacería. Todo lo ofrecen para que cualquiera entre en tentaciones y acreciente su compulsión por comprar y así desbocado llene los carritos con productos, ya que todo está tan a la mano, tan cerca de uno, tan fácil de tomar. Se sale de uno de estos mercados tan anónimamente como se ingresó.

En estos lugares de expendio masivo se ofrece al público platillos elaborados, algunos de los cuales se venden al peso, y entre tantas tentaciones se encuentra también tamales puestos a la mano en fechas y durante celebraciones convenientes. El problema no es que estén en rumas y siempre fríos, lo que sucede es que son hechos "industrialmente" por mujeres a las que nunca se ha visto ni se ha conversado con ellas y, en consecuencia, no son nuestras íntimas, no les conocemos el rostro y si hay algo malo en el producto no hay nadie a quien reclamarle ni, por el contrario, ofrecerle una felicitación por la exquisitez de su producto, ni hay la posibilidad de llevarle como agradecimiento una florcita en el Día de la Amistad. Los que se venden en los supermercados son tamales inhumanamente anónimos, no dicen ni trasmiten cariño ni nada. Pero son competencia. Y no son los únicos.

\section{De muchos sitios cercanos llegan tamales a Lima Metropolitana}

Lima con su gran población es un gran mercado al que muchos y variados vendedores pretenden llegar para ofrecer sus productos. Las productoras de tamales de provincias próximas a la capital ya hace varias décadas venden en lugares fijos o caminando por las calles de Lima Metropolitana. No pocas tamaleras de los valles costeños de Chincha, Mala, Cañete, Chancay-Huaral, Huacho-Huaura, Supe, BarrancaPativilca, Huarmey llegan regularmente a la ciudad capital, sobre todo los fines de semana, con el objetivo de vender sus tamales. Por eso, entre viernes y domingos, los omnibuses ${ }^{5}$ que tienen como destino Lima y que salen de esos valles llevan

$5 \quad$ En realidad el precio de estos omnibuses no es tan elevado y son frecuentes sus idas y venidas. 
siempre como pasajeros a vendedoras de tamales y otros productos de sus zonas.

En cuanto a estas tamaleras de provincias que llegan a Lima regularmente, se dan algunas situaciones:

- Las que viven en sus poblados de origen y los fines de semana viajan a Lima para realizar sus ventas.

- Las que pasan en Lima los fines de semana y algunos días más. En este ir y venir van abandonando sus lugares de origen a donde llegan casi exclusivamente para preparar y llevar la producción tamalera a Lima porque en sus poblados tienen la facilidad de conseguir los insumos a menor precio.

- Las que residen en Lima y desde sus lugares de origen les envían semanalmente los tamales y otros productos comestibles lugareños. La tendencia en este último caso es que estas tamaleras ya residentes de la capital, hagan también tamales en la gran ciudad pero que han tenido que hacer modificaciones como por ejemplo el uso de la carne de pollo que ha desplazado al tradicional chancho que fácilmente lo tenían (o criaban) en sus lugares de origen.

Lo que interesa de estas migrantes temporales es que a los limeños consumidores nos presentan una gran gama de sabores de tamales así como otros productos exquisitos que por tradición hacen en sus pueblos. Un buen consumidor de tamales aprende a percibir las variaciones en cuanto a la sazón: blanquiñosos y aguachentos los de Supe, granulados y algo secos los tamales cuadrados de Chincha que tienen cierta cercanía con la carapulcra, los dulcetes — comparables a las humitas — de los pueblos próximos a Huancayo, que no son muy grandes y siempre están envueltos con panca y a su vez con hoja de plátano, etc. De cualquiera de estos sitios las tamaleras han sucumbido ante la exigencia del mercado limeño por los tamales de pollo y esto se ven obligadas a hacer.

En Lima, dentro del mundo de los tamales, se sabe que el distrito de Surco es, desde mucho tiempo antes, un lugar de gran producción tamalera. De la parte antigua de este distrito se dice que en una de cada tres casas se prepara tamales; y por su larga experiencia son buenas vendedoras. Así, cuando las tamaleras surcanas aparecen las otras se quejan y dicen: "ya llegaron las surcanas". Es que son serias competidoras y por eso se les teme, "las surcanas tienen su fama". Se dice que estas productoras tamaleras (de tamal largo), así como las chinchanas (de tamal cuadrado), son las que el consorcio Wong, en algún momento, las escogió para que elaboraran los tamales que aún se venden en sus casi 30 súper o hípermercados. De allí que las otras vendedoras tamaleras tradicionales han perdido algo de su clientela. No son las únicas en lamentarse, igual lo hacen otros comerciantes que cerca de esos gigantes se sienten perdedores en la competencia.

\section{La comida china entre los limeños}

En el Perú hay un impresionante consumo de comida chino-cantonesa (de la provincia sureña china de Guandong) pues desde el siglo xIX, a partir del año 1849, hasta la actualidad, año 2011, la corriente migratoria desde ese país asiático no se 
ha detenido; durante ciento sesenta años ha sido continua pero en muy diversas intensidades según lo que sucedía en China o según lo que acontecía en la sociedad peruana.

Estos asiáticos en los lugares del mundo donde se establecieron - tener en cuenta que hay una importante diáspora china surgida por emigraciones involuntarias y voluntarias - han difundido sus incomparables delicias de mesa, sea en bocadillos, sopas, "segundos" y postres, bebidas. Asimismo han aportado técnicas, insumos, fusiones recreativas, todo esto altamente sofisticado y apreciado. La culinariagastronomía es la fuerza de esa cultura milenaria, pero atrás de ella hay concepciones filosóficas confucianas y creencias en el yin y el yan que la explican pero que casi en ninguna parte las han asimilado.

$\mathrm{Al}$ igual que en muchos otros lugares, los peruanos solo hemos tomado lo superficial de esta culinaria-gastronomía, nos hemos hecho rutinarios, siempre pedimos los mismos platos como si no hubiera muchísimos otros. Pero lo hemos hecho con una profusión sorprendente, única en casi todo el continente americano; tanto que no hay en Lima un solo mercado, mercadillo, súper o hípermercado donde no se venda productos comestibles de origen chino. Lo que sucede es que esos productos (desde sillao, kión y muchas verduras chinas) nos son habituales a la vista y al paladar y ya no nos parecen extraños ni de otras latitudes. Tampoco pensamos en por qué hay tan amplia difusión de los platillos en una cantidad tan sorprendente que el chaufa parece peruano y hasta le hemos hecho innovaciones para peruanizarlo aún más. No hay casa en Lima que no prepare su chaufita y para los domingos, por ser fáciles de hacer, se han popularizando los tallarines saltados, el wantán frito, la sopa wantán.

Ya se ha olvidado o no se conoce que en los inicios de la inmigración china del siglo XIX, miles de chinos culíes que cumplían sus trabajos obligatorios de las haciendas cañeras y algodoneras, se dedicaron a vender comida en pequeños restaurancitos muy populares a los que se llamaba "fondas" y que existían antes de ellos. Desde las fondas difundieron justamente esos tallarines saltados y ese arroz chaufa. $\mathrm{Y}$ es así como poco a poco los peruanos fuimos aprendiendo a saborear y aceptar las viandas de la comida chino cantonesa.

Aproximadamente en la década de los años 30 del siglo xx, aparece como palabra ya en uso el vocablo chifa, que servía para designar lo que antes se llamaba "fonda" y después restaurantes de comida oriental. Esto sucedía en el Barrio Chino de Lima y al mismo tiempo en buena parte de la costa peruana donde la evolución o el paso de fonda a restaurante y luego a chifa ocurrió de manera similar; casi paralela; mas en Lima las dimensiones siempre fueron mucho mayores.

¿Por qué se hizo atractiva la comida china? Habría que precisar qué nos atrae a los costeños que a los serranos, y entre los costeños más a los que residen en Lima. Esto debido a que los costeños han sido aleccionados silenciosamente en el consumo de esa comida oriental durante varias generaciones por cocineros chinos que físicamente han estado muy cerca y que con cada nueva oleada de chinos inmigrantes han persistido en esas lecciones silenciosas.

En el transcurso de tantas décadas, de una manera muy sutil percibida por esos cocineros, hemos ido seleccionando lo que más nos agradaba y desechando lo que 
no era muy de nuestro gusto. Lo que mayormente consumimos en la actualidad es resultado de ciertas preferencias, de cierto decantamiento; hay productos y viandas desechados por los peruanos que los chinos de China no excluyen y que a veces los consumen ante nuestros ojos.

Actualmente la gastronomía china en Perú y preferentemente en Lima, muestra su gran vitalidad de varias maneras.

\section{Vivimos en tiempos de esplendor del chifa}

Un asunto principal por considerar es que el número de chifas y hasta el consumo casero ha ido en aumento de manera impresionante. En 1998 realizamos con estudiantes de Nutrición de la Universidad Nacional Mayor de San Marcos una encuesta a chifas. Una de las preguntas estuvo referida al año en que estas abrieron. El resultado que se obtuvo fue el siguiente:

\begin{tabular}{|l|r|r|}
\hline Periodos & \multicolumn{1}{|c|}{$\mathbf{N}^{\circ}$} & \multicolumn{1}{c|}{$\%$} \\
\hline Antes de 1983 & 40 & 5.8 \\
\hline $1984-1988$ & 73 & 10.6 \\
\hline $1989-1993$ & 219 & 31.7 \\
\hline $1994-1998$ & 335 & 48.6 \\
\hline $\mathrm{n} / \mathrm{s}, \mathrm{n} / \mathrm{c}$ & 23 & 3.3 \\
\hline Totales & 690 & 100 \\
\hline
\end{tabular}

Años de aparición de chifas (por quinquenios)

De los 690 chifas a los que se pudo llegar y encuestar, 554 (80.3 \%) abrieron sus puertas entre 1989 y 1998, importante periodo político, económico y social donde lo más destacado fue el recomienzo de la pacificación debido a la derrota de la subversión senderista que asoló el país por varios años, cuyo momento más importante fue el 12 de septiembre de 1992 con la captura de Abimael Guzmán, principal dirigente del grupo Sendero Luminoso.

Este despertar del interés por los chifas y muchos otros negocios — según se muestra en el cuadro-, sucede junto con una nueva oleada de inmigrantes chinos, que empezó de a pocos por los años 90 del siglo xx y que con el paso de los años ha ido en aumento. Esta inmigración no procede esta vez de Guandong, de la etnia puntí, sino de la provincia de Fujián de la etnia hakká; que viene con capitales de origen incierto y sin conocer casi nada del idioma castellano. Pero contando con el seguro esfuerzo de sus familias, estos chinos abren chifitas de barrios y los llamados chifas al paso. A ellos se les reconoce porque su español es incipiente.

A esta presencia se agrega buena cantidad de locales instalados en las últimas décadas que venden esta misma comida pero cuyos propietarios son peruanos, los chifas cholos, que conocen la elaboración de los platos más comúnmente consumidos de la culinaria china. 
En el diario El Comercio del 17 de diciembre de 2001, con el título "De China a Perú en Combi", se informaba a los lectores sobre la existencia de comida china al paso en el cono norte de Lima donde la simplificación era tanta que los platillos que se ofrecían al público eran solo sopa wantán, arroz chaufa y tallarín saltado. A propósito, hace pocos años ha aparecido una variante del chaufa, de gran aceptación: el aeropuerto; y se llama de esta manera porque allí aterrizan todos. Y aún de manera reciente hay una variante más llamada chaufa salvaje.

Este fenómeno de los chifas peruanos se da en muchos locales próximos entre sí. Son administrados y atendidos por peruanos y la comida también es preparada por ellos; no hay ningún chino cerca. Igual fenómeno culinario-gastronómico-cultural ocurría y continúa igual en muchas partes de la gran Metrópolis. El humor popular llama a estos restaurantes "chifas cholos", donde al igual que los chinos que recién han llegado, al cholo peruano, propietario de su empresita, se le ve sudoroso con su wok en la mano, tirando por los aires el arroz chaufa, el tallarín saltado o el aeropuerto para con igual destreza recibirlo sin que caiga al suelo ningún grano del cereal o ningún fideo y así, humeante, aromático, provocativo, colocarlo en un recipiente y ofrecerlo al ansioso cliente.

Otra variante a través del tiempo es la forma tradicional en que los chifas sirven sus platillos; anteriormente era en fuentes de las que los comensales trasladaban a sus platos lo que deseaban, unos consumían con palillos y la mayoría con tenedor. Ahora han surgido y se han expandido con intensidad los menús con platos de consumo personal.

Asimismo, actualmente se observa otra manera de consumir en los chifas: el llamado buffet. Consiste en que cada cliente paga un precio fijo que le permite comer en las cantidades que desea de los amplios recipientes que tiene a la vista, en mesas destinadas a este fin, cada fuente o sopera con una vianda diferente. $Y$ hasta hay cada vez más chifas en Lima que ofrecen al mismo tiempo buffet chino y buffet de comida criolla, lo que permite combinaciones de muchos sabores, olores y colores.

En cuanto a la técnica de venta delivery no es adoptada de manera intensa por los chifas. Tal vez no la utilizan porque se considera que comer comida china es un momento familiar o social (personas de un mismo trabajo, festejos, aniversarios, etc.) y que solo se aprecia en un local amplio ante una mesa, bien sentado y bien conversado; además, ¿para qué hacer un pedido por teléfono si, por lo general, siempre hay cerca uno de estos restaurantes orientales?

Referente a los platos tradicionales, la gastronomía china ofrece en tiempos recientes el dim sum que corresponde a muy variados bocaditos cocinados al vapor. Los más conocidos son el mimpau, siu mai, jacau, koc chay, cha siu pao, siu lam, kay piy san sey cao, que se pueden consumir en cualquier momento: como parte del desayuno o como lonche, con algún té; también como entrada antes de los platos de fondo, y ya son parte de los manjares al paso, se los ve en las calles del Barrio Chino y en muchos supermercados de la capital.

El chifa en Lima es panlimeño, lo encontramos en cualquier lugar de la ciudad; hay chifas de todo tipo, muy antiguos y muy recientes, hay los que son de chinos y los que son de peruanos. Están muy a la mano. Perduran algunos chifas por los que han 
pasado tres generaciones de orientales aunque no siempre sean generaciones de un mismo apellido, lo que no ha cambiado es el nombre del restaurante oriental.

\section{El infaltable chaufa y la importancia del aeropuerto}

La palabra chaufa viene de chau fan o arroz frito. Nos importa porque es el platillo más demandado en chifas donde van sectores sociales A y B y en otros donde concurren sectores $\mathrm{C}$ y D, se le encuentra en otros restaurantes que no son chifas y es, entre todo otro platillo oriental, el que más conocen y hacen en sus hogares las amas de casa o quien cocine. Es tanto este interés que los dueños de chifas saben que hay especialistas en elaborarlos a los que se les denomina chauferos. En 1935, con cierta timidez, ya la receta del chaufa era ofrecida por la revista Oriental ${ }^{6}\left(\mathrm{~N}^{\circ}{ }^{0} 38\right.$, mes de abril, p. 81) para difundirla, y pocos años después, aparecía en un libro editado en el Perú el año $1937^{7}$ y actualmente no hay jefa de casa, fundamentalmente en la costa, que la desconozca. Incluso en los supermercados es usual encontrar el picadillo chaufa consistente en una mezcla de varios embutidos cortados en cuadraditos. Y en los chifas así como en otros restaurantes, ofrecen chaufa en diferentes variedades con innovaciones peruanas: con carne de res, con mariscos, con camarones, con langostinos y lo que es tradición de siempre, con pollo o carne de cerdo. La peruanización de este plato ha llegado a tal punto que a veces se come con ají y hay recetas de chaufa de quinua $^{8}$ en el que, por supuesto, se reemplaza al arroz por ese nutritivo cereal andino.

En el poblado cusqueño de Urubamba encontramos que en la pollería Los Candiles y en el restaurante Las Nustas ofrecen chaufa con bistec. Un chino diría:

$6 \quad$ La revista Oriental es la más antigua en Lima, su primer número apareció el año 1931. Transcribimos para satisfacer sanas curiosidades lo que se dice en el libro y que puede remitirnos a comparar con alguna de las recetas actuales que conocemos del arroz chaufa que hasta en la obra que citamos le colocan otro nombre: "Arroz Chifa. Se mata un pollo gordo y se pone a cocinar en agua caliente, con lo siguiente: un trozo de apio, un poro, o cebolla blanca, un nabo, una cebolla corriente, un tomate partido en dos, sal y pimienta; cuando el pollo está bien cocido, se quita del fuego y se saca toda la carne de los huesos, en trozos no muy pequeños y de esta carne se toma solo las partes blancas del pollo. Luego en una cacerola se fríe lo siguiente: tres ataditos de cebolla china que se picará bien menudita hasta la mitad de las hojas verdes, luego de fritas se le agrega unos ajos machucados (dos o tres), ochenta centavos de jamón inglés, un ají mirasol tostado despepitado y molido hasta reducirlo a polvo. Todo esto se fríe bien en aceite fino.//El arroz se hace corrientemente con su buena cantidad de manteca y se deja al rescoldo. Luego se fríen cuatro o cinco huevos procurando que las yemas endurezcan bien, luego se cortan en pedazos no muy chicos y se añaden al frito anterior, se revuelve todo muy bien y entonces se agrega a todo esto el pollo descuartizado y lo último es el arroz que con todo lo anterior se revuelve bien echándole unas cuatro cucharadas de aceite y se deja reposar a fuego lento unos cinco minutos. No se pone en molde”. En: Libro de Recetas de Cocina, s/autor, s/edit, Perú, 1937, pp. 27 y 28.

8 Quinua (Bot. Chenopodium quinoa), cereal oriundo de los andes peruanos, se cultiva en alturas de 3.000 a 4.000 m.s.n.m. De la quinua se aprovecha todo. 
comida de kuei; ese mismo chino diría lo mismo si viera que al chaufa le echamos sillao o salsa de soya. Para un peruano no es posible un arroz chaufa sin sillao, esta es una manera de haberlo peruanizado según nuestra preferencia gustativa.

Un derivado de impresionante aceptación que no tiene mucho tiempo entre los aficionados chiferos limeños es el denominado aeropuerto, que es un chaufa al que se le añade algo de tallarines chinos y también frejolitos chinos. Las observaciones muy precisas del periodista Toño Angulo Daneri en artículo que redactó para el diario El Comercio ${ }^{9}$ nos ofrece la manera cómo se hace un aeropuerto y el ambiente del chifa El Olímpico, que antes se llamó El Cajamarquino, ubicado en la esquina de la Panamericana Norte y la avenida Los Próceres, en el distrito limeño de San Martín de Porres. Angulo Daneri nos dice:

Aquí viene. Genaro (que lleva el apodo de Chino sin serlo) vierte en su sartén gigante un chorro de aceite Oro $100 \%$ vegetal y $0 \%$ colesterol, luego un poco de manteca $100 \%$ de cerdo y una vez que el líquido rompe en burbujas y empieza a echar humo, pone a flotar unos trozos de pollo y de cerdo. Cuando el gallináceo y el porcino acaban de broncearse, Genaro agrega los demás ingredientes: col china, cebolla ídem, pimientos en tiras, sal, aji-no moto, kión y media taza de caldo que extrae de un balde de plástico Rey. Hasta ahora parece un saltado, nada fuera de lo común, aunque huele bien. ¿Y el aeropuerto, chino? Falta. Llegan los frejolitos chinos, una buena ración de arroz y un generoso baño de sillao con chuño diluido en otra cucharada de caldo. Esta vez parece un arroz chaufa que se computa aguadito aguadito, con frijolitos y col china. Pero no: he aquí el ingrediente que faltaba y que llega para elevar el plato a la categoría de aeropuerto: una contundente ración de tallarines cortados en trozos pequeños. Ahora sí. Genaro remueve todo con su cucharón, tira la mezcla por los aires, espera que caiga sobre la sartén, y al plato. Sale el aeropuerto humeante ${ }^{10}$.

El periodista nos da una explicación muy necesaria: "se llama aeropuerto porque allí (en el wok) aterriza de todo”. Ese chifa, El Olímpico, no está solo en esa esquina, a su izquierda están también los chifas El Ancashino, Osorio y Rosita, y a su derecha Sholy y Lilian y Lindo Amanecer, seis chifas en no más de 200 metros cuadrados, de los cuales ninguno de sus propietarios es chino. Con unas cuantas líneas más podemos percibir la poca amplitud de los pedidos de los comensales en estos restaurantes:

El aeropuerto es el plato más celebrado, pero no es el único. El chifa

$9 \quad$ ANGULO DANERI, Toño, "De China a Perú en combi”. En: El Comercio, Lima, 17 de diciembre del 2001.

10 Ibídem. 
Rosita se encarga de resumir la reiterada oferta gastronómica. Enorme pizarra rectangular con dragón verde fosforescente que escupe fuego por la boca, y letras rojas y amarillas que anuncian la triada básica: sopa, tallarín y chifa. ¿Chifa? Sí, chifa. Según la pizarra de Rosita, chifa no es la voz que designa la comida chino-peruana, sino el arroz chaufa. ${ }^{11}$

En algunos de los chifas al paso de la ciudad ya tienen preparados de antemano estos tres reiterativos platos y los exhiben de manera impresionante, como si fuese una pequeña loma. No es desacertada, entonces, la manera cómo algunos comensales solicitan su chaufa o su aeropuerto, que en el plato sea "todo un cerro". Hay por último - aunque no muy generalizado - un último derivado del aeropuerto llamado chaufa salvaje, cuya peculiaridad y diferencia es que en vez del tallarín chino se le ingresa variadas verduras chinas y que, por hacer notar su presencia y por considerarlo atractivo lo anuncian en gigantografías y en los comunes menús.

Lo mencionado en el último párrafo indica la muy creciente actitud imaginativa culinaria a partir de un simple arroz chaufa, el hecho sucede en el distrito limeño de Villa el Salvador y seguramente es muy similar en muchos de los distritos populares de Lima Metropolitana aunque no tanto en provincias. Todo este boom por unos cuantos platillos chinos parece ser solo limeño.

En una zona del distrito Villa el Salvador donde están nueve restaurantes de comida china, cercanos a un sector industrial importante y de éxito, administrados por sus propietarios, inmigrantes chinos que alcanzaron bonanza económica debido al gran interés del vecindario, por consumir sobre todo platillos elaborados con arroz, preferentemente el arroz chaufa, el aeropuerto y otras recreaciones, encontramos un gran uso de este cereal, que se refleja en los datos que siguen:

\section{Consumo semanal de chaufa y variantes en chifas de Villa el Salvador, $2007^{12}$}

\begin{tabular}{|l|r|r|r|r|}
\hline Chifas & $\mathbf{N}^{\circ}$ de sacos & Kilos & Platos & Venta \\
\hline Ji Li & 20 & 1020 & 5100 & 24400 \\
\hline Huan Sim & 12 & 600 & 3000 & 12000 \\
\hline When Wa & 80 & 4000 & 20000 & 100000 \\
\hline Shen Ha & 16 & 800 & 4000 & 20000 \\
\hline Fu Lin & 16 & 800 & 4000 & 20000 \\
\hline Fu Ping & 7 & 350 & 1750 & 8750 \\
\hline Wha Li & 7 & 350 & 1750 & 8750 \\
\hline Fu Gut & 8 & 400 & 2000 & 10000 \\
\hline Totales & $\mathbf{1 6 6}$ & $\mathbf{8 3 2 0}$ & 41600 & 203900 \\
\hline
\end{tabular}

\section{Ibídem.}

12 Fuente: Monografía de curso universitario de UNMSM, 2007, de Manuel Calle Ignacio "El chifa y los chinos en Villa el Salvador". 
En el cuadro se coloca que el consumo es chaufa y variantes aunque se debe aceptar que en esas cantidades hay otros usos muy menores del arroz, sea como guarnición de cualquier "segundo" consistente. De todas formas, al igual que en otros sitios de Lima Metropolitana y cualquiera sea la clase social, el plato más demandado en chifas es el chaufa. Se muestra también en el cuadro el número de sacos consumidos durante una semana por cada chifa, información fidedigna por la manera cómo el autor, un estudiante de antropología obtuvo sus apuntes. Los datos en la columna "platos" se conocen por preguntas realizadas en los chifas (de un kilo de arroz se obtienen cinco chaufas) y conociendo el precio de cada chaufa se ha logrado saber lo que los comensales han pagado por cada uno de esos platillos. Uno solo de los chifas, When Wa, es el que consigue vender casi el $50 \%$ de todos los chaufas que semanalmente se venden y por eso su facturación y ganancias son, no solo notables sino impresionantes. En la actualidad, el When Wa sigue siendo el más conocido y el más exitoso por la calidad de sus viandas, se sabe que tiene una cocina bien equipada, trabaja con mozos uniformados, ha abierto un nuevo ambiente para atender al público que desea consumir al momento. Pero los más interesados aún continúan siendo aquellos clientes que llevan su comida, para lo cual hacen colas inmensas desde antes de mediodía hasta las 4 de la tarde. Todo el personal que cocina y atiende en este chifa es de origen peruano, al lado de la cajera se ve a una mujer de origen chino, que seguramente es una de las dueñas, está encargada de supervisar todos los pedidos y de guardar el dinero.

La variedad de arroces chaufas y sus precios actuales (octubre 2009) tal como aparecen en la carta son: con pollo S/.5.50, con chancho S/.6.50, con pollo y chancho S/.7.50, con carne S/.7.50, con pollo en trozos S/.8.50, especial S/.9.00, con langostinos $\mathrm{S} / .11 .00$. Y en cuanto a la variedad de aeropuertos y sus precios actuales son: con pollo S/.6.50, con chancho S/.7.50, con pollo y chancho S/.8.50, con carne $\mathrm{S} / .8 .50$, especial S/.10.00, con langostinos S/.12.00, con trozos de pollo S/.10.00. Seguramente similares ganancias se dan en los seis chifas de esa esquina del distrito de Villa el Salvador y debe ser igual en muchas otras partes de esta Lima chifera y chaufera $^{13}$.

\section{Comida china en la mesa familiar de todos los días}

En Lima y en muchas partes de la costa y también incursionando en sierra y selva, las amas de casa han ido aprendiendo a hacer platillos chinos. Es un fenómeno irreversible posiblemente porque hacer chifa en casa es muy sencillo, no es difícil encontrar los insumos y los paladares de la gente de la casa ha sido seducida por los sabores y aromas orientales. Digamos que esta seducción se reduce a pocos platillos que

13 Es lamentable que Perú mucho gusto, libro editado por Promperú y difundido a precio bajo y muy ampliamente en el país y fuera de él, no contenga ninguna referencia ni receta del arroz chaufa ni de sus variantes, negación de una realidad peruana tangible y masiva. 
seguramente irán en aumento puesto que hay interés de ampliar las recetas que se conocen que por lo demás es fácil ver nuevas propuestas en la televisión en programas gastronómicos o en folletines difundidos por los diarios.

\section{Chifas como exportación peruana}

Como noticia reciente la revista dominical del diario limeño La República nos informaba que se estaban desarrollando de manera óptima franquicias nacionales de marcas de cadenas de restaurantes que iban abriendo locales en el país y en el extranjero. Entre las tres que mencionaba colocaba a Chinawok, es así que de esta manera el chifa peruano estaba viajando por otros lares. La idea que había surgido en 1999 pretendía “... llevar el chifa de nivel gastronómico a un consumo masivo y rápido" y hacerlo al igual que otras cadenas internacionales de renombre. El primer local se abrió en un centro comercial limeño, esta misma tónica continuó en otros centros comerciales de la capital; hasta que pasó la frontera del norte y llegó a Ecuador a partir de la inquietud de inversionistas ecuatorianos que, obtenida la franquicia, ubicaron el chifa en el Centro Comercial Entre Ríos de Guayaquil. A partir de ahí el crecimiento fue rápido; locales de Chinawoks aparecieron en El Salvador, Guatemala, Costa Rica, Panamá y Chile. Actualmente, además de los mencionados, en nuestro país funcionan diecinueve de sus locales y pronto se abrirían puntos de venta en México, Colombia y Venezuela ${ }^{14}$. Lo novedoso en este caso es que los propietarios de esta cadena no tienen antecesores chinos, sus apellidos son peruanos.

Si bien este parece ser el caso más notable, ya desde décadas anteriores la idea o la realidad del chifa era algo que estaba presente en países vecinos; en Chile en tanto la tradición china era continuidad de la presencia de chinos inmigrantes desde el siglo XIX en departamentos que ahora están en el norte de ese país en provincias que antes fueron peruanas y bolivianas; y en el caso de Ecuador en tanto la frontera con este país fue muy sensible y permisible a la ida y venida de los chinos, sea que ingresaban con ayuda de sus connacionales "de contrabando"15, sea que se trasladaban de Perú a Ecuador o viceversa cuando económicamente les era conveniente.

\footnotetext{
14 LOAYZA, Jorge. Franquicias y delicias, en: Domingo, revista dominical de La República, Lima, 27 de abril del 2008.

15 En Sullana me informaron hace algunas décadas que un chino que residía en esa ciudad y que aún mantenía una tienda bastante grande había sido el que más se dedicó al negocio de contrabando de sus paisanos en tiempos, — seguramente durante el ochenio de Odría- en que era prohibido el ingreso de asiáticos a Perú; con este fin había adquirido una hacienda que justamente colindaba con Ecuador, se dice, que al que recién ingresaba recibía nombre y apellido de algún chino que no hacía mucho tiempo había fallecido y que su estadía en el Perú fue de manera totalmente legal. También recuerdo que en el año 1951 cuando mi padre que era militar y estaba destacado en Piura, su trabajo era estar enterado lo que ocurría en la frontera y él mencionaba ese mismo contrabando humano.
} 
En Ecuador desde siempre ha habido más chifas en Guayaquil que en Quito. En la Capital ecuatoriana el chifa más reconocido y aceptado es peruano, y su nombre es Joy Tim. Según los lugareños es famoso por su excelente tallarín saltado con pollo.

\section{BIBLIOGRAFÍA}

ANGULO DANERI, Toño, 2001 "De China a Perú en combi", en El Comercio, Lima, 17 de diciembre ARONA, Juan

1972 La inmigración en el Perú. Academia Diplomática del Perú, Lima.

BALBI, Mariella

1999 Los Chifas en el Perú: Historia y Recetas. Ediciones Universidad de San Martín de Porres, Lima.

BARRIG, Maruja

1977 “Chifas. Una historia con sabor", en Dominical, suplemento dominical de El Comercio, Lima, 22 de mayo, 10 y 11.

BASADRE, Jorge

1969 Historia de la República del Perú. Ts. I-XVI, Editorial Universitaria, Lima, 6ta Edic.

BENVENUTTO MURIET'TA, Pedro M.

1983 Quince Plazuelas, una Alameda y un Callejón. Fondo del Libro Banco Industrial, Lima.

CALLE IGNACIO, Manuel

2007 "El chifa y los chinos en Villa el Salvador" monografía presentada en el curso Antropología de Minorías Étnicas, conducido por Humberto Rodríguez en la E.A.P. de Antropología, Universidad Nacional Mayor de San Marcos.

CAMINO CALDERÓN, Carlos

1945 Diccionario Folklórico del Perú. Cía. de Impresiones y Publicidad, Lima. FUENTES, Manuel Atanasio

1988 Lima, Apuntes Históricos, Descriptivos, Estadísticos y de Costumbres. Fondo del Libro. Banco Industrial del Perú.

GÁLVEZ, José

1935 Estampas Limeñas. s/edit, Lima, enero.

$\mathrm{HO}$, Christine

1989 "Hold the Chow Mein, Gimme Soca: Creolization of the Chinese in Guyana, Trinidad and Jamaica", en Amerasia Journal. Vol.15, N 2, 3-25 pp. University of California, Los Angeles, EE.UU. 
HU-DeHART, Evelyn

1988 "Chinos comerciantes en el Perú: breve y preliminar bosquejo histórico (1869-1924)”, en Primer Seminario sobre Poblaciones Inmigrantes. T. II. $127-135$ pp.

LAUSENT-HERRERA, Isabelle

1992 "Lima au coeur de la ville, le quartier chinois", en Problemes d'Amerique Latine. N. ${ }^{\circ} 14$, julio-septiembre, pp 311-319.

1993 "Les Chinois du Pérou: une identité reconstruite", en Journal de la Société des Américanistes. Vol.80, pp 169-183.

MAYER DE ZULEN, Dora

1924 La China silenciosa y elocuente. Editorial Renovación, Lima, 180 pp.

McKEOWN, Adam

1996 “Inmigración China al Perú, 1904-1937; Exclusión y Negociación”, en Histórica, Vol. xx N. ${ }^{\circ}$ 1, julio.

MIDDENDORF, Ernst

1973 "Mercados de Lima (1976)", en Núñez, Estuadro, El Perú visto por viajeros. T.I. La Costa, pp.172-184.

1973 Perú. Ts. I, II y III., Universidad Nacional Mayor de San Marcos. Trad. Ernesto More.

MILLONES, Luis

1973 Minorías Étnicas en el Perú. Ed. Andina S.A., Lima.

MING CHUNG, HO

1967 Manual de la Colonia China en el Perú s/edit, 66 pp (en castellano), 16 pp (en chino)

MORE, Ernesto

1935 "Gracias a los chinos, el Perú, huérfano totalmente de tradición culinaria, está aprendiendo la ciencia y el arte de comer. Filosofía de los palillos y exégesis del pacifismo a través del yantar". En: Cascabel, N. ${ }^{\circ} 38$, sábado 18 de mayo.

PROMPERÚ

2009 Perú mucho gusto

RODRIGUEZ PASTOR, Humberto

1989 Hijos del Celeste Imperio en el Perú (1850 1900). Migración, agricultura, mentalidad y explotación. Editado por el Instituto de Apoyo Agrario, Lima, $318 \mathrm{pp}$.

1993 "Del Kon Hei Fat Choy al chifa peruano", en OLIVAS WESTON, Rosario (editora) Cultura, Identidad y Cocina en el Perú. Universidad de San Martín de Porres, Lima, pp.189-238.

2000 Herederos del Dragón. Historia de la colonia china en el Perú. Editado por el Congreso de la República.

2006 "La pasión por el chifa", en Nueva Sociedad. N. ' 203, Buenos Aires, Argentina, mayo-junio, pp. 79-88 
STEWART, Watt

1974 Servidumbre China en el Perú. Ed. Mosca Azul, Lima. El título original en inglés fue Chinese Bondage in Peru. A History of the chinese in Peru (1849-1874). Duke University Press, 1951, Estados Unidos de Norteamérica.

TAURO DEL PINO, Alberto (coordinador de la preparación).

1996 Diccionario Enciclopédico del Perú. Ts. I-III. Editorial Mejía Baca.

TRAZEGNIES, Fernando.

1994 En el País de las Colinas de Arena. Tomos I y II, Pontifica Universidad Católica, Fondo Editorial, Lima.

VALDERRAMA, Mariano.

1997 Gastromanía. La guía de oro de la comida peruana. Promperú, 3era Edic. Lima

WIENER, Charles.

1991 Perú y Bolivia. Coedición Instituto Francés de Estudios Andinos (IFEA) y Universidad Nacional Mayor de San Marcos. Lima. 